\title{
Thermal Imaging in Aviation
}

\author{
Marek Štumper \\ Laboratory of Aviation Safety and Security \\ Department of Air Transport, Faculty of Transportation \\ Sciences, Czech Technical University in Prgue \\ Horská 3, Praha 2, 128 03, Czech Republic
}

\author{
Jakub Kraus \\ ATM Systems Laboratory, \\ Department of Air Transport, Faculty of Transportation \\ Sciences, Czech Technical University in Prague \\ Horská 3, Praha 2, 128 03, Czech Republic \\ e-mail: kraus@fd.cvut.cz
}

\author{
Ladislav Capoušek \\ Department of Air Transport \\ Faculty of Transportation Sciences, Czech Technical University in Prague \\ Horská 3, Praha 2, 128 03, Czech Republic
}

\begin{abstract}
This article focuses on the use of thermal imaging in aviation. In the never ending pursuit of lower costs, the Thermal Imaging offers shorter inspection times thanks to its application in aircraft inspections and can reduce the number of costly goarounds using the Enhanced Vision System, which also increases safety in one of the most dangerous parts of flight. Thermal Imaging also offers solutions for Airport Perimeter Security and it can be used for construction of ground surveillance system.
\end{abstract}

Keywords-thermal imaging; non-destructive evaluation; enhanced vision system; surveiilance; safety

\section{INTRODUCTION}

Aviation is one of the world leaders in researching and applying new technologies that aim to increase safety and security, but also to decrease costs. The effects of thermal (infrared) radiation have been known for a long time, but thermal imaging is relatively young field. Aviation industry quickly spotted the potential of using infrared cameras for several purposes and began studying the possibilities of their use. They proved to be useful in aircraft maintenance for nondestructive evaluation of materials, the Enhanced Vision System gives pilots better situational awareness in low visibility conditions and the cameras can offer an additional way of patrolling the perimeter of airports.

\section{WHAT IS THERMAL IMAGING}

Every object with a temperature greater than absolute zero emits electromagnetic waves which are called thermal radiation. This radiation is generated by kinetic motion of charged particles in the matter. The amount of radiation emitted increases with temperature. Both visible and infrared lights are examples of thermal radiation, but human eye is limited in what it can see: it can see the difference between hot and cold metal, but cannot see the thermal radiation of a building. This article focuses on the use of infrared light that is invisible to human eye, but with a proper technology it can be detected and processed into an image.
Thermal imaging is a part of infrared imaging science (in this case imaging things that the human eye cannot detect). The thermal radiation is detected and processed into an image which can be seen by human eye. This is done in a device called thermal imaging camera (also called infrared camera).

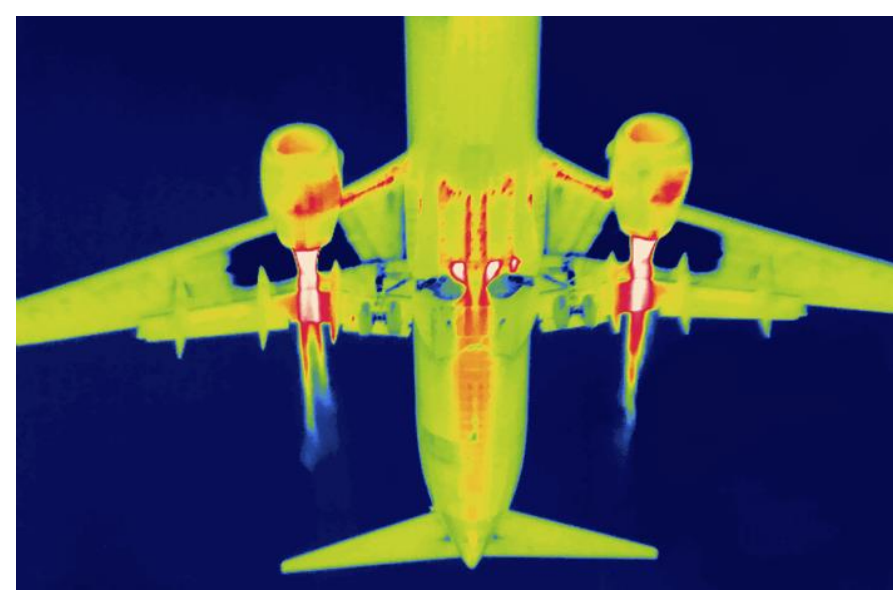

Figure 1. Thermal Image of an aircraft [3]

As stated above, any object with a temperature higher than absolute zero emits thermal radiation, therefore it is possible with thermal imaging to see objects of interest without any visible illumination. This fact makes thermal imaging a technology that can be used in various parts of aviation industry.

\section{APPLICATION OF THERMAL IMAGING IN AVIATION}

There are several ways how to use Thermal Imaging in aviation, both from safety and security point of view. This article discusses: Non-destructive evaluation of materials, Enhanced vision systems, Airport security, Surveillance Systems and other uses, that do not necessarily benefit aviation, but aviation plays a key role in them. 


\section{A. Non-destructive evaluation of materials}

Aircrafts are made of variety of materials, such as aluminium and composites. During its life cycle, an aircraft has to withstand large amount of pressurizations, depressurizations, temperature changes, vibrations, etc. Although they are constructed to the safest manner possible, all those events can cause a defect to develop in a material. It is important for maintenance shops to have a method that enables them to find those defects within a short period of time and with a high level of certainty.

One method is the use of thermal imaging. A heat flow is applied on the part to be inspected. It can be done either by applying energy in pulsed form or in a harmonic modulated way (i.e. halogen lamps). The temperature of inspected object is recorded with a thermal imaging camera and an appropriate mathematical analysis is applied [5]. An image is calculated which shows the internal structure of the object with (or without) defects.

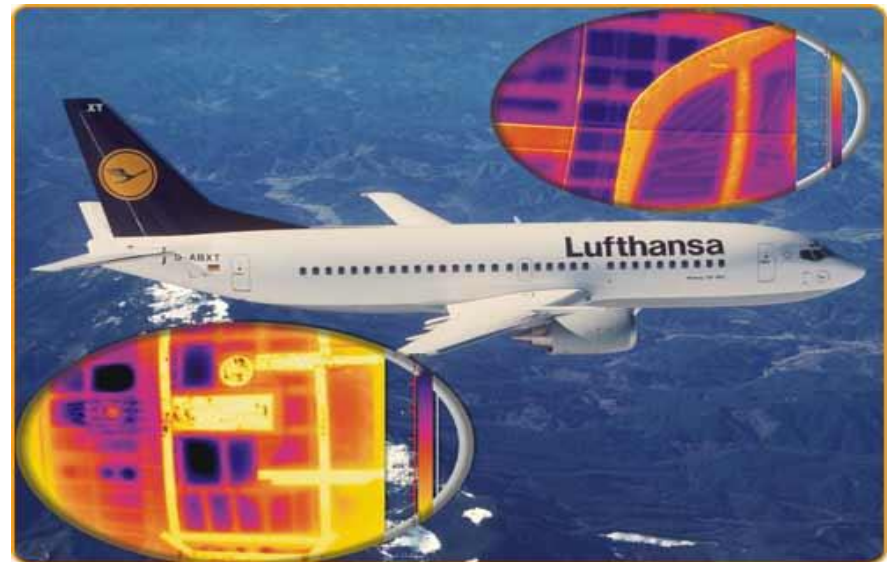

Figure 2. Images of aircraft parts taken during non-destructive inspection [4]

The Lufthansa Technik studied the use of thermography in 2001 and according to Peter Feddern, Lufthansa NDT engineer, one complete inspection takes approximately 100 hours. This represents a time-saving of about 1000 hours [4].

\section{B. Enhanced Vision System (EVS)}

Enhanced vision system uses and infrared camera mounted on the front lower side of an airplane to offer pilots enhanced image of outside situation. From the thermal imaging principles mentioned above, it is clear that the infrared camera can reveal objects with various temperatures, even if the human eye cannot see them. Even at night, in light fog or rain, the advanced technology of EVS reveals taxiways, runway markings, adjacent highways and surrounding terrain, offering pilots better situational awareness and making landing, takingoff and taxiing safer.

The processed image is usually displayed on the Head-updisplay (HUD) so it does not require any additional monitors in the cockpit.

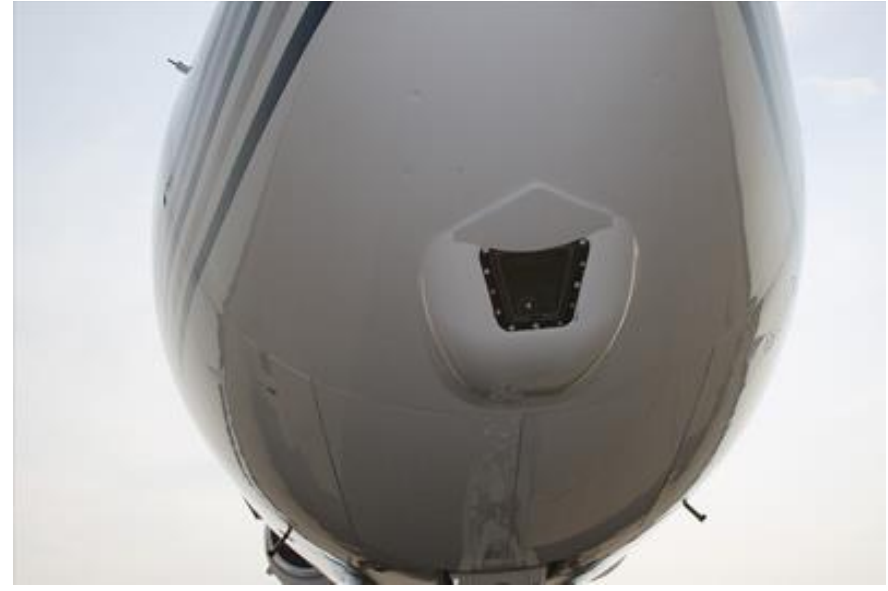

Figure 3. Infrared camera mounted on the airplane [7]

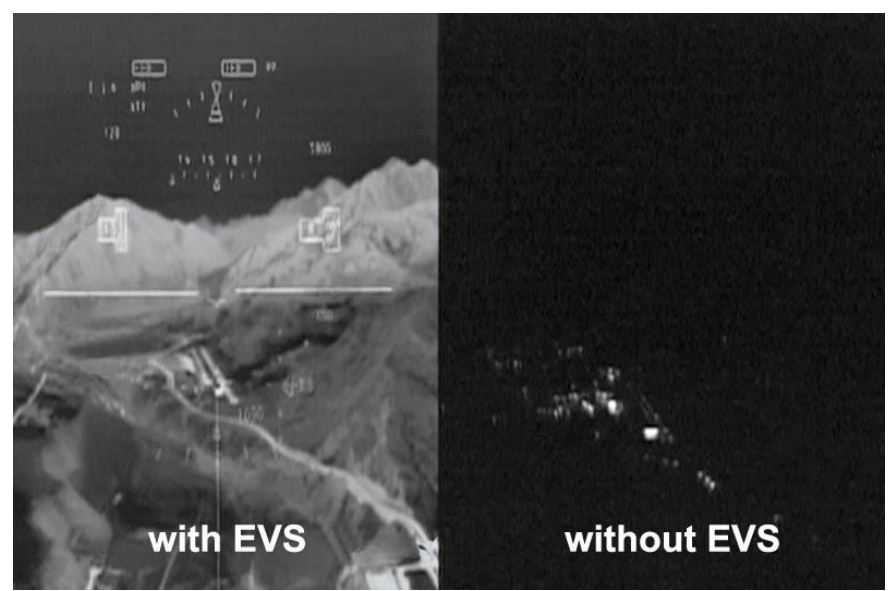

Figure 4. Comparison of view with EVS and without EVS [6]

\section{Airport Security}

Airport perimeters are typically protected by man-made barriers, such as fences or in less frequent cases by natural barriers, such as bodies of water or cliffs. Additionally, security patrols check the perimeter for signs of intrusion [9]. This, however, does not necessarily prove to be ideal for airports, where it is hard to do a perimeter check. Use of automated sensors might be an option how to increase security and make eventual response more effective.

The sensors might include CCTV systems, movement sensors or infrared sensors with automated detection and warning features.

\section{Surveillance systems}

The field of aviation surveillance systems using thermal imaging cameras is still considered experimental, but there is a reasonable belief it could be utilized. The principle is to position several cameras in defined positions and heights around the movement area and use the function of hottest spot detection (which is assumed to be an aircraft). By knowing the coordinates of the cameras and the coordinates of the hottest spot on the camera output, the real coordinates of an object can be calculated [10]. 


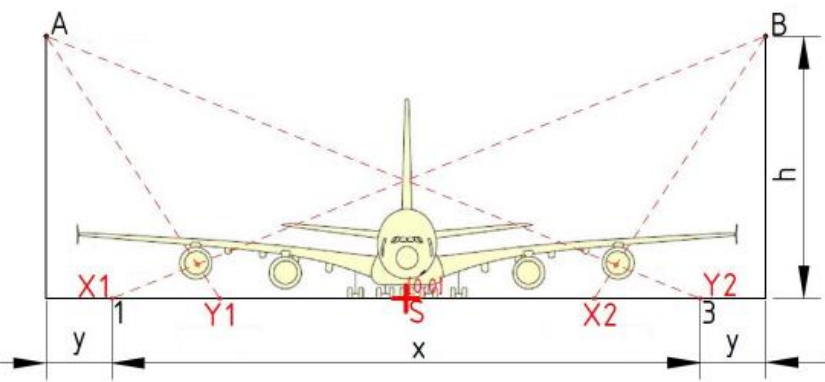

Figure 5. Potential use of infrared cameras for surveillance system [10]

\section{AVAILABLE HARDWARE}

In general, there are multiple companies offering thermal imaging cameras, from simple, cheap ones to very sophisticated and expensive systems. But only several companies offer solutions for aviation applications, such as Non-destructive evaluation of materials or EVS.

FLIR Systems, Inc. is the world's largest company specializing in thermal imaging cameras, components and sensors. It was founded in 1978 and offers thermal cameras for variety of commercial and government applications [11]. The aviation industry is not excluded and the company offers variety of products for EVS and Airport Security. Although not promoted by FLIR, their cameras (A310f) can be used to build a surveillance system.

Deducing from the research done on internet, the largest number of companies offering their products to aviation can be found in the field of Enhanced Vision System. The very first manufacturer to introduce EVS on their aircraft was Gulfstream Aerospace using Kollsman IR camera [12]. Other business jet manufacturers followed (Bombardier, Dassault) and in 2010 the EVS was certified by FAA on Boeing Business jets [13]. Besides the Kollsman, Inc., the EVS is offered by Rockwell Collins, Thales, Elbit systems of America, FLIR Systems, Inc. or Astronics Max-Viz.

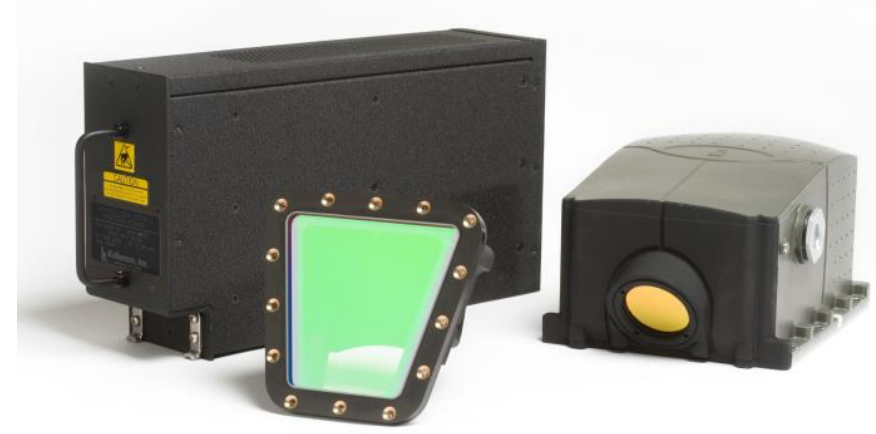

Figure 6. System offered by Elbit Systems of America [14]

For the Non-destructive evaluation of materials application, company called moviMED was found. It offers its JET-
CHECK Aircraft Inspection System which is certified by FAA and currently used by Lufthansa Technik, Boeing and Airbus [4].

\section{CONCLUSION}

The main aim of this article is to provide a introduction into the use of thermal imaging in aviation. Several types of possible applications are discussed and outcomes of research of available hardware are presented. It is indisputable, that thermal imaging has a lot to offer to aviation in increasing both safety and security while reducing costs.

\section{ACKNOWLEDGMENT}

This paper was supported by the Grant Agency of the Czech Technical University in Prague, grant No. SGS15/172/OHK2/2T/16.

\section{REFERENCES}

[1] Termokamera.cz Tepelné záření - Termokamera.cz | Průvodcem světem termokamer. Termokamera.cz Termokamera.cz - Portál pro uživatele termokamery | Průvodcem světem termokamer [online]. Available from: http://www.termokamera.cz/princip-a-funkce/tepelne-zareni/

[2] About Thermal Imaging. Thermal Scopes [online]. (C)2015. Available from: https://thermalscope.com/about-thermal-imaging

[3] Tyrone Turner Takes Thermal Imaging Up, Up and Away | PROOF National Geographic: Images of Animals, Nature, and Cultures [online]. March 3,2014. Available from: http://proof.nationalgeographic.com/2014/03/03/tyrone-turner-thermalimaging/

[4] Thermography Solutions. Machine Vision Systems and Imaging Systems by MoviMED [online]. Available from: http://www.movimed.com/aircraft_inspection_system.html

[5] Active Thermography for Nondestructive Composites Testing | 2013-0705 | Quality Magazine. Quality Magazine | Information \& news for manufacturing professionals in quality assurance and process improvement. [online]. July 5,2013. Available from: http://www.qualitymag.com/articles/91207-active-thermography-fornondestructive-composites-testing

[6] Hospodka, J.: Lowering the Impact of Aviation on Global Earth's Radiation Balance. Transactions on Transport Sciences. 2012, vol. 5, no. 4, p. 189-194. ISSN 1802-971X.

[7] G550 Technology - Gulfstream. The World's Most Advanced Business Jet Aircraft - Gulfstream [online]. (C2014. Available from: http://dev.gulfstream.com/products/g550/technology.htm

[8] Gulfstream Aerospace - Aircraft - G450. Gulfstream Aerospace - The World's Most Advanced Business Jet Aircraft [online]. (C2015. Available from: http://www.gulfstream.com/aircraft/gulfstream-g450

[9] Thermal Imaging for Port \& Border Security | FLIR Systems. FLIR Systems | Thermal Imaging, Night Vision and Infrared Camera Systems [online]. C2015. Available from: http://www.flir.com/security/content/?id=69087

[10] Elias, Bartholomew. Airport and aviation security: U.S. policy and strategy in the age of global terrorism. Boca Raton, FL: CRC Press, c2010, xxvii, 411 p. ISBN 14-200-7029-0.

[11] Hospodka, J.: Cost-benefit analysis of electric taxi systems for aircraft. Journal of Air Transport Management. 2014, vol. 20, no. 39, p. 81-88. ISSN 0969-6997

[12] Skálová, M.: Přehledový systém tvořený soustavou termovizních kamer. 2014. ČVUT v Praze

[13] About FLIR Systems. FLIR Systems | Thermal Imaging, Night Vision and Infrared Camera Systems [online]. (C2015. Available from: http://www.flir.eu/aboutFLIR/ 
[14] Enhanced Vision System - SKYbrary Aviation Safety. SKYbrary Aviation Safety [online]. 20March2015n. 1. Available from: http://www.skybrary.aero/index.php/Enhanced_Vision_System

[15] FAA Certifies Enhanced Vision System on Boeing Business Jet - Oct 18, 2010. Boeing: The Boeing Company [online]. October 18, 2010. 1.
Available from: http://boeing.mediaroom.com/2010-10-18-FAACertifies-Enhanced-Vision-System-on-Boeing-Business-Jet

[16] Elbit. Elbit [online]. (C2015. Available from: https://www.elbitsystems.com/elbitpr/pic/EVS\%20II.jpg 